\title{
Tonality of the Concept "Refugee" in the German Mass-Media Discourse of Different Political Content
}

\author{
Adelia Grigorievna Khasanova*, Tatyana Yakovlevna Zaglyadkina, Alfiya Nailevna Zaripova, \\ Olga Valerevna Akimova
}

Kazan Federal University, Republic of Tatarstan, Russian Federation

Received: 02/06/2020

Accepted: 28/09/2020

Published: 20/12/2020

\begin{abstract}
Recently, there have been profound social, political and economic changes in Europe, associated with a huge influx of refugees. The relevance of the studied language problem is connected with the changes that took place in Germany which have influenced the state, political parties and the population's attitude towards refugees, and, in particular, the presentation of the unresolved problems of the hosting and integration of refugees in the publicist discourse. About four years have passed since the crisis began, however, many topics still cause controversy and discussion, which in turn is reflected in the press. The article aims to analyse the tonality of the concept "Refugee" in the German mass-media discourse of different political content. The leading method of the research is the sentiment analysis of the studied concept "Refugee" using sentiment dictionaries and considering articles from liberal (Die Tageszeitung (Taz)), conservative (Deutschland Kurier) and social-democratic newspapers (Stern). As a result of the analysis, it has been found that the social-democratic Stern is the newspaper with the most negative tonality with the arithmetic average of 0.184 . The liberal newspaper Die Tageszeitung (Taz) has depicted the refugee crisis with more positive publications with the arithmetic average of 0.374 . The conservative newspaper Deutschland Kurier, with the arithmetic average of 0.269 , is in the middle. During the analysed period, Stern has $58 \%$ negative, $40.3 \%$ positive and $1.34 \%$ neutral publications. Taz has $53 \%$ positive and $47 \%$ negative publications, without any neutral articles at all. Deutschland Kurier has more negative materials $(57 \%)$ than neutral $(28 \%)$ and positive materials (15\%). The materials of the article can be applied in linguistics, stylistics and lexicology of the Russian and German languages; in linguistic regional geography and intercultural communication. The method of dictionary-based sentiment analysis may find further application of the political discourse tonality analysis.
\end{abstract}

Keywords: Refugee, Concept, Higher education, Linguistics, Communication, Tonality, Corpus linguistics, Sentiment analysis, Computational linguistics, Dictionary-based sentiment analysis

\section{Introduction \\ 1.1 The relevance of the problem}

For many years, the problem of the interaction between people, language and culture has been the focus of attention of many linguistic studies. Each language has its way of reality conceptualization, which is characterized by both national and individual features [1, p. 127]. Concept is a central component of "conceptology, a section of interdisciplinary cognitive science" $[2, p .4]$. A concept is an element of the worldview mediated by a language; a person's knowledge and opinion of an object [3]. Many Russian linguists studied concepts, but, despite the keen interest in this phenomenon, the very definition of the concept remains very vague. In other words, the generally accepted definition of concept does not exist yet. The huge interest of both Russian and foreign linguists in the notion of concept explains the relevance of this study. Concept, as a structure of knowledge, "combines all aspects of a person's cognitive activity, therefore, it contains the perceptual, sensory-motor, emotional and linguistic components" [4, p. 248-251]. Speaking about the emotional component of the concept, it should be noted that emotions are closely connected with the evaluation category; and tonality is one of the most important means of expressing this category. Through tonality, the author's subjective attitude towards reality is transmitted [5, p. 68]. The recent profound changes in Germany that affected all the spheres of its social, political and economic development are also reflected in the linguistic sphere. According to A.M. Alekseeva and E.M. Bulatova, text is a communicative unit, the emotional component of which makes it possible to interact with the audience and affect its opinion [6]. The analysis of the newspapers from the five largest European countries, conducted by M. Berry, I. Garcia-Blanco and K. Moore, showed that the issue of refugees remains relevant in each of the abovementioned countries. At the same time, Germany turned out to be a country where the citizens' opinion and its weight in the mass media were the most valuable. If to compare it to Italy and France, the German newspapers articles covered the humanitarian aspects of the refugee problem to a much lesser extent. M. Berry, I. Garcia-Blanco and K. Moore found out that the most

Corresponding author: Adelia Grigorievna Khasanova, Kazan Federal University, Republic of Tatarstan, Russian Federation. E-mail: wedance.wesing@gmail.com 
dissatisfaction with the policies of Angela Merkel and her party was shown by liberal, left-wing sources. At the same time, other European countries presented the refugee problem as a threat to the security and preservation of the cultural code to a much greater extent than Germany. However, this does not mean that the attitude towards refugees was positive. M. Berry, I. GarciaBlanco and K. Moore emphasize that the German newspapers publish few materials that would focus on the benefits of hosting refugees for the economic and cultural situation in the country [7].

B. Holzberg, K. Kolbe and R. Zaborowski come to some different conclusions: their analysis of the German mass media regarding the refugee problem showed more negative public sentiments. In particular, B. Holzberg and colleagues found out that the image of a refugee in mass media is the image of a person who is considered in terms of disadvantages or advantages for the host country. Accordingly, the German newspapers articles ignore the reasons for the crisis and pay attention to the presence of refugees, which is considered a heavy burden [8, p. 534-550].

However, it is worth mentioning that such generalizations do not take into account the political pluralism of the German newspapers. Nowadays, the German press freedom is guaranteed by the state and the Constitution, which is explained by the diversity and wide range of mass media in the country. The importance of journalists and editorial staff is so great that the press in Germany is called the "fourth power", which performs a monitoring and educational function. Each of the political content has its sources through which it expresses its views and opinions. G. Nordheim, H. Müller and M. Scheppe believe that there are obvious differences in how traditional and right-wing mass media cover the refugee problem. Using the 2015-2016 newspaper articles as an example, the authors of the research show that rightwing newspapers such as Junge Freiheit raise negative sentiment and ignore more detailed aspects of the problem [9, p. 38-56]. In 2017 , M. Haller criticized the review of the refugee crisis and said that the events of 2015-2017 deepened the split between the mass media of different political content, making each of the positions more radical [10].

As for the Germans themselves, recent studies show that they do not have a pronounced, unambiguous attitude to the problem. $59 \%$ of the Germans are concerned about the influx of refugees, but at the same time, they are aware of the economic benefits associated with their presence in the country [11]. Moreover, many of them believe that helping people who are forced to leave their countries because of a life-threatening situation is the moral duty of a prosperous European country. As for conceptology, according to the study by O.G. Palutina, the presence of controversial elements in the structure of concept is not uncommon. The concept's associations may contain both positive and negative elements [12, p. 251-255].

In its turn, the analysis of the text's tonality as a special class of natural language processing is gaining popularity in computational linguistics. Machine texts analysis conducted to highlight the emotional component shows the fast pace of the development as well as promising prospects. In particular, machine methods allow one to process great amounts of texts, while its manual analysis would be time-consuming. Foreign studies have already dealt with the tonality analysis of political texts, but they have mostly focused on analysing the social networks discourse and short materials such as posts on Twitter. For example, A. Bermingham and A. Smeaton used data from Twitter to predict the results of the US presidential race, basing on the tonality of the expressed opinions [13, p. 2-10]. The novelty of the research is in the attempt to use the method of dictionary-based sentiment analysis applied to the newspapers articles.

This research was aimed at identifying the tonality of the concept "Refugee" in the publicist discourse, using the example of a newspaper article genre.

\subsection{Research Hypothesis}

There are concepts in German linguistic culture, that are implemented in the discourse process of the language system, have a certain specificity and lend themselves to linguistic research. The concept "Refugee" considered in publicist discourse is such a concept. This concept cannot be analysed in isolation from the context of newspapers, namely, from the political situation in Germany and the significant difference in the attitude to migration and refugees among representatives of various political factions. The null hypothesis of the study is the absence of differences between the representation of the concept "Refugee" in sources of different political content. The alternative hypothesis suggests the presence of these differences.

\section{Methods}

\subsection{Aims of the research}

The following objectives were pursued in the research: 1) machine analysis of the concept "Refugee" considering articles from online versions of the conservative (Deutschland Kurier), liberal (Die Tageszeitung (Taz)) and social-democratic newspapers (Stern); 2) determination of the tonality of the studied concept "Refugee" and its classification into three categories: negative, positive or neutral; 3) finding the interconnections between the concept "Refugee" and emotional concepts.

\subsection{Theoretical and Empirical Methods}

The following methods were used in the research:

Theoretical: analysis of text lexical units collected from online newspapers, their study and generalization, synthesis;

empirical: dictionary-based sentiment analysis. Nowadays, there are several sentiment dictionaries of the German language. We used SentiWortschatz (SentiWS) [14], which contains 1,650 negative and 1,818 positive words in the range $(-1 ; 1)$ for the analysis. Another reason to choose SentiWS, in addition to its rich content, was its focus on political and social vocabulary, which makes it suitable for analysing the political newspapers articles. The second sentiment dictionary, German Polarity Lexicon ("PolArt" -Lexicon) [15] contains 3,424 positive, 5,294 negative and 662 neutral nouns, verbs and adjectives. The third dictionary, German Emotion Dictionary [16], differs from the previously mentioned, as it does not determine the tonality of the text (negative or positive). Its purpose is to identify emotions in the text, such as fear, joy, anger and others. To calculate tonality, an algorithm was written in the Python programming language. The general tonality of each text is understood as the difference between the sum of all individual negative indicators and the sum of all individual positive indicators. The model was validated using an error matrix that showed a classification accuracy (f-1) of $83 \%$ for a liberal source, $80 \%$ for a social-democratic source and $70 \%$ for a conservative source.

\subsection{Research base}

The study was based on sources that differ in political content. 
The selection criteria were: (1) a belonging to a political party; (2) the popularity of the source; (3) the availability of online versions and a sufficient number of free materials. Selection according to criteria excluded most potential sources, which allowed us to concentrate on the three of them:

Taz - an alternative liberal source, which criticizes the political system of Germany;

Deutschland Kurier - a conservative, right-wing source, which states to be "independent, non-traditional and affordable";

Stern - a social-democratic source.

The selection of articles was carried out manually according to the method of continuous sampling. In data collection, representative tokens such as "Flüchtling" and "Asylsuchende" became key tokens. Articles on the situation in Germany and not in other countries were prioritized. As a result, 135 articles from Taz, 139 articles from Deutschland Kurier and 149 articles from Stern were collected.

\section{Results}

According to Figure 1, the largest variation in the tonality of the concept "Refugee" was shown by the social-democratic source Stern with the distinct low points in March, August and September. In addition to the dynamics calculated on the basis of monthly average values, the graph also shows general trends in the form of straight lines. The more positive tonality of the liberal source Die Tageszeitung (Taz) (rising line) can be noticed. Despite the controversial attitude of the Stern source to the object under study, over the year the tonality has changed rather to a positive one. The same, however, cannot be said of the conservative source Deutschland Kurier, the tonality of which has acquired more negative connotation over the year (descending line). Table 1 contains a comparative analysis of the tonality of the concept "Refugee" in the examined sources. The arithmetic average makes it easy to notice that Stern has the most negative tonality $(0.184$ for the selected range $[-1 ; 1])$. The liberal source Die Tageszeitung (Taz) shows the most positive tonality with the arithmetic average of 0.374. Materials taken from the conservative source Deutschland Kurier have an average tonality of 0.269. Big values of the standard deviation of the sources Stern and Deutschland Kurier mean a larger variety of values in the presented set with the average value. In other words, these sources have more materials with enhanced positive or negative tonality. Thus, the standard deviation of Deutschland Kurier is 0.374 , of Stern -0.341 , while for Taz it reaches only 0.236. At the same time, the liberal source Taz contains more articles with a clear positive attitude towards the concept "Refugee". This is evidenced by the presence of an upper limit, as well as by a relatively high value of the lower quartile $(0.280$; while for other sources, it equals to 0.105 and 0.02 ). On the contrary, the most negative materials were found in the conservative source Deutschland Kurier.

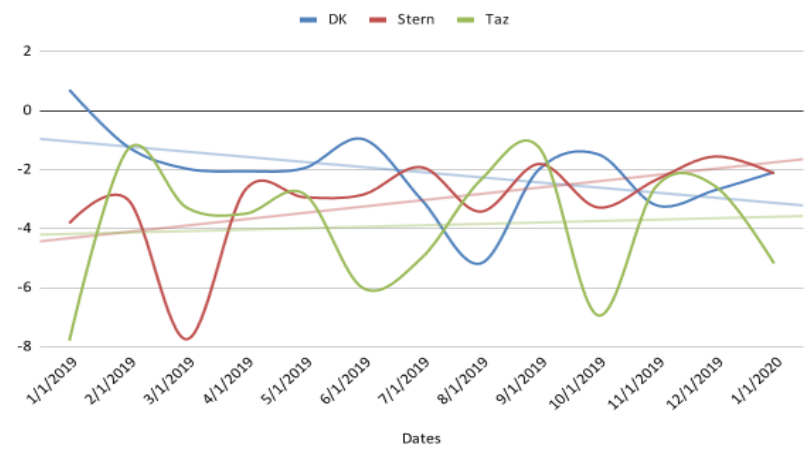

Figure 1: The tonality changes of the concept "Refugee" in the examined sources from January 2019 to January 2020

The classification of source materials showed that the conservative newspaper Deutschland Kurier has the greatest number of negatively coloured materials (57\%), followed by neutral $(28 \%)$ and positive materials $(15 \%)$. Analysis of the liberal source Die Tageszeitung (Taz) did not reveal the presence of neutral-coloured materials at all. At the same time, a certain prevalence of positive materials $(53 \%)$ over negative $(47 \%)$ was found. The largest percentage of negative materials was found in the social-democratic source Stern (58\%). Positive and neutral materials are outnumbered $(40.3 \%$ and $1.34 \%$, respectively) (Figure 2). Each of the examined sources showed a certain connection with the emotional concepts of "contempt", "fear", "joy", "surprise", "sadness", "anger", and "disgust". In each of the sources, the vast majority of lexical units have no emotional colouring. However, the smallest proportion of neutral lexical units was found in the liberal source Die Tageszeitung (92.8\%). The largest neutrality was shown by the conservative source Deutschland Kurier (94.1\%). Figure 3 demonstrates that in liberal and conservative sources the most obvious connection is with the emotional concept of "contempt", while in social-democratic it is with the concept of "fear". Perhaps, contempt is understood in the liberal source as a criticism of the authorities' inaction regarding refugees and inadequate assistance, while the conservative source is contemptuous towards the hosting of refugees and the use of public resources.

Table 1: Descriptive statistics on the tonality of the concept "Refugee" in the examined sources

\begin{tabular}{|l|c|c|c|}
\hline & Taz & Deutschland Kurier & Stern \\
\hline Number of measurements & 135 & 139 & 145 \\
\hline Arithmetic average & 0.374 & 0.269 & 0.184 \\
\hline Standard deviation & 0.236 & 0.374 & 0.341 \\
\hline Upper limit (Q1 + 1.5IQR (Interquartile range))* & 0.775 & - & - \\
\hline Q1 (lower quartile**) & 0.280 & 0.105 & 0.020 \\
\hline Q2 (median) & 0.394 & 0.293 & 0.198 \\
\hline Q3 (upper quartile) & 0.499 & 0.530 & 0.414 \\
\hline Lower limit (Q3 + 1.5IQR (Interquartile range)) & -0.042 & -0.455 & -0.53 \\
\hline
\end{tabular}

$*$ The difference between upper and lower quartiles.

** A quartile is a type of quantile, which divides the number of data points into four more or less equal parts, or quarters $(25 \%, 50 \%, 75 \%, 100 \%)$ 
The liberal source Die Tageszeitung is the only newspaper, in which materials on the refugee concept are linked to the concept of "joy". At the same time, the liberal newspaper demonstrates the weakest connection between the examined concept "Refugee" and the emotional concept of "disgust".

\section{Percentage of texts of a certain tonality}

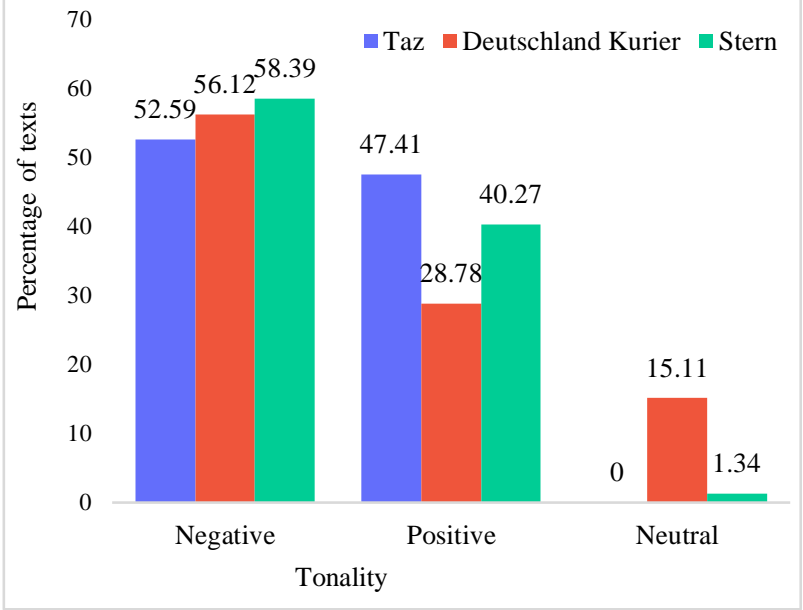

Figure 2: Percentage of texts of a certain tonality of the concept "Refugee"

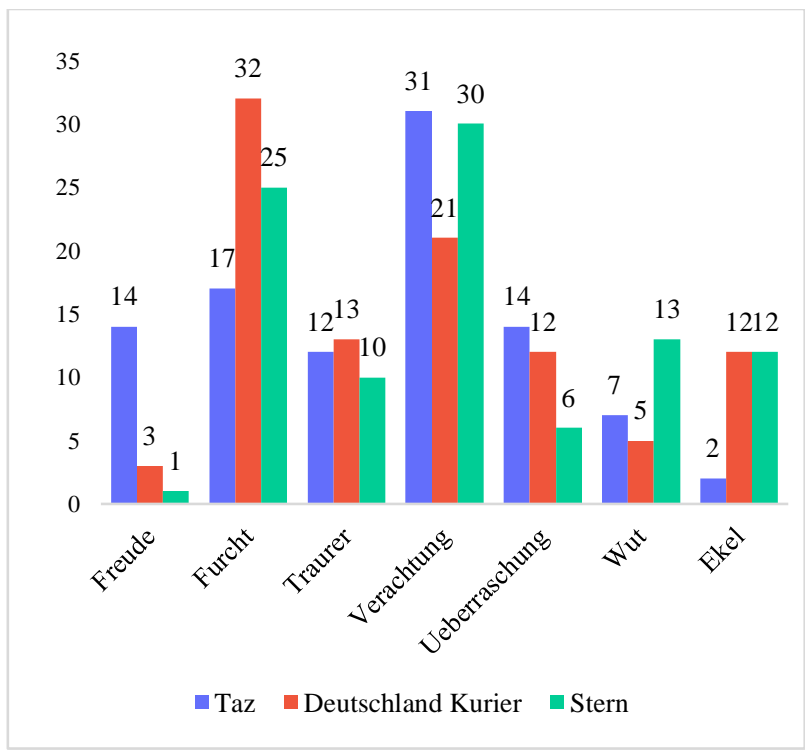

Figure 3: The interconnections between the concept "Refugee" and emotional concepts in the examined sources

\section{Discussion}

Summing up, we can conclude that the alternative hypothesis of the research was confirmed. There are quite noticeable differences in the tonality of the concept "Refugee" in sources of different political content, which was also found out in the recent study by G. Nordheim, H. Müller and M. Scheppe [9]. Despite the fact that about four years have passed since the crisis began, the topic remains relevant and it causes polar opinions and reactions in mass media. In all the three sources, materials with neutral tonality are outnumbered or not present at all. At the same time, the newspapers may reflect mixed emotions and the ambiguous attitude of the Germans. All the three sources are not fully negative or positive, as well as the Germans who can see the two sides of the problem: the complexity of the crisis and promising prospects. This conclusion contradicts a little to M. Haller's theses that there is a clear division in the German mass media, which deteriorate continuously.

M. Berry, I. Garcia-Blanco and K. Moore point out that there is both the absence of a predominant humanitarian element in covering the refugee problem and the levelling of the threat to economic and social stability. Our study showed that although this characteristic applies to the German mass media as a whole, different sources still have their unique characteristics. The humanitarian element is more obvious in the liberal source, while the conservative source associates refugees with violence, crime and danger.

The present study showed the attitude of various German newspapers towards the concept "Refugee" in terms of tonality. Such studies have not yet been conducted previously. However, despite all its advantages, this research still has drawbacks. First, the machine-based text classification model showed certain accuracy only for the liberal and social democratic corpora, which questions the reliability of the results for the conservative corpus of texts. The lower effectiveness of the model based on the dictionary-based sentiment analysis when analysing a conservative source can be explained by the widespread use of sarcasm. Determining the true intentions of sarcastic texts is still a difficult task for machine methods of processing natural language. Second, we examined newspapers publications made during only one year (2019), which does not allow us to conclude the dynamics of the tonality changes in press.

Further research may focus on developing a more accurate text classification model and analysing large volumes of materials. Besides, the analysis of political texts offers a wide range of possible areas of research, such as thematic modelling and forecasting the development of public opinion regarding a concept.

\section{Conclusion}

The analysis of the tonality of the concept "Refugee" in the German mass media discourse of various political content demonstrates results: 1. During the examined period (from January, 2019 to January, 2020), the most significant negative tonality was shown by the social-democratic source Stern. The liberal newspaper Die Tageszeitung, in comparison with Stern, reacted to the refugee crisis with more positive publications. The tonality of the conservative newspaper Deutschland Kurier is in the middle. 2. The arithmetic average of Stern is 0.184; the one of Deutschland Kurier is 0.269; and for Die Tageszeitung it is 0.374 . It allows the Social Democratic source to have the most negative tonality. 3. Considering the above-mentioned newspapers from the point of view of positive, neutral or negative tonality, we can conclude that the social-democratic newspaper source Stern has $58 \%$ of negative, $40.3 \%$ of positive and $1.34 \%$ of neutral 
publications. The liberal newspaper Die Tageszeitung has 53\% positive and $47 \%$ negative publications. There are no neutrally coloured articles. Finally, in the conservative source Deutschland Kurier negative materials are in the top position (57\%), while neutral materials and positive publication are only $28 \%$ and $15 \%$ respectively.

At the beginning of the study, as an alternative hypothesis, we assumed that newspapers would differ in the tonality of the concept "Refugee", which was confirmed by the results. We plan to examine the dynamics of the tonality changes of the concept "Refugee" during 2020 in our further research.

\section{Ethical issue}

Authors are aware of, and comply with, best practice in publication ethics specifically with regard to authorship (avoidance of guest authorship), dual submission, manipulation of figures, competing interests and compliance with policies on research ethics. Authors adhere to publication requirements that submitted work is original and has not been published elsewhere in any language.

\section{Competing interests}

The authors declare that there is no conflict of interest that would prejudice the impartiality of this scientific work.

\section{Authors' contribution}

All authors of this study have a complete contribution for data collection, data analyses and manuscript writing.

\section{References}

1. Pimenova VM. Tipy kontseptov i etapy kontseptualnogo issledovaniya [The concepts types and the stages of conceptual research]. Vestnik KemSU. 2013; 2-2(54):127-131.

2. Karasik VI, Sternin IA, editors. Antologiya kontseptov [Concepts anthology]. Vol. 1. Volgograd: Paradigma; 2005. p. 4.

3. Sakaeva LR, Salyakhova GI, Yahin MA, Burenkova OM. Methodological Bases of Conceptology: Features and Structure of the Linguo-Cultural Concept. Revista San Gregorio. 2018; 23:100106.

4. Kravchenko AV. Funktsionalno-kognitivnyi analiz yazykovykh edinits i ego applikativnyi potentsial [Functional and cognitive analysis of linguistic units and its applicative potential]. In: Materials from the first international conference of 5-7 October, 2011. Barnaul: AltGPA; 2011. p. 248-251.

5. Tupikova SE. Kategoriya tonalnosti i urovni ee reprezentatsii $v$ zhanre svetskoi khroniki [The category of tonality and its representation levels in the genre of society pages]. Voprosy kognitivnoi lingvistiki [Cognitive linguistics problems]. 2011; 4(29):68-73.

6. Bulatova AM, Alekseeva EM. Lexical Objectivation Means For The Emotional Concept "Fear" In German Publicistic Discourse. The Turkish Online Journal of Design, Art and Communication. 2016; 6(Special Edition):2334-2339.

7. Berry M, Garcia-Blanco I, Moore K. Press coverage of the refugee and migrant crisis in the EU: A content analysis of five European countries; 2015. Available from: https://www.unhcr.org/56bb369c9.pdf (accessed June 5, 2020).

8. Holzberg B, Kolbe K, Zaborowski R. Figures of crisis: The delineation of (un) deserving refugees in the German media. Sociology. 2018; 52(3):534-550.

9. Nordheim G, Müller H, Scheppe M. Young, free and biased: A comparison of mainstream and right-wing media coverage of the 2015-16 refugee crisis in German newspapers. Journal of Alternative and Community Media. 2019; 4(1):38-56.
10. Haller M. Die „Flüchtlingskrise“ in den Medien. Tagesaktueller Journalismus zwischen Meinung und Information. Otto Brenner Schtiftung; 2017. Available from: https://www.otto-brennerstiftung.de/fileadmin/user_data/stiftung/02_Wissenschaftsportal/03 _Publikationen/AH93_Fluechtingskrise_Haller_2017_07_20.pdf (accessed June 5, 2020).

11. Mosel I, Smart C, Foresti M, Hennessey G, Leach A. Public narratives and attitudes towards refugees and other migrants; 2019 Available from: https://www.odi.org/sites/odi.org.uk/files/resourcedocuments/12970.pdf (accessed June 5, 2020).

12. Palutina OG. Conceptual Structure of SLAVA/FAME/RUHM in Russian, American and German Consciousness. Journal of Sustainable Development. 2015; 8(5):251-255.

13. Bermingham A, Smeaton A. On using Twitter to monitor political sentiment and predict election results. In: Proceedings of the Workshop on Sentiment Analysis where AI meets Psychology, (SAAIP), IJCNLP 2011, Chiang Mai, Thailand, November 13, 2011; 2011. p. 2-10.

14. Remus R, Quasthoff U, Heyer G. SentiWS-A Publicly Available German-language Resource for Sentiment Analysis. In: Proceedings of the 7th International Language Resources and Evaluation (LREC'10); 2010. p. 1168-1171.

15. Klenner M, Fahrni A, Petrakis S. Polart: A robust tool for sentiment analysis. In: Jokinen K, Bick E, editors. Proceedings of the 17th Nordic Conference of Computational Linguistics (NODALIDA 2009), Odense, Denmark, May 14-16, 2009. Northern European Association for Language Technology (NEALT); 2009. p. 235-238.

16. Klinger R, Suliya SS, Reiter N. Automatic emotion detection for quantitative literary studies - a case study on Kafka's "Das Schloss" and "Amerika". In: Digital Humanities 2016: Conference Abstracts, Kraków, Poland; 2016. p. 826-828. 